\title{
O sistema de ensino em serviço social pós Bolonha: uma visão crítica
}

The education system in social work post Bologna: a critical point of view

\section{Resumo:}

\author{
Maria Irene Carvalho \\ Hélia Bracons Carneiro ** \\ Ana Paula Garcia *** \\ João Daniel Veiga ${ }^{* * * *}$
}

\begin{abstract}
Este artigo tem como finalidade compreender, numa perspectiva crítica, o Ensino Superior, em Portugal, Pós Bolonha, para evidenciar o modo como o Serviço Social se adequou a este processo. Essa modificação no ensino superior teve alterações substantivas no que diz respeito à sua configuração, temporalidade e acesso. Os cursos de formação-base, em nível das licenciaturas, que, em Portugal, eram de dez semestres, passaram para seis ou sete semestres. $O$ acesso foi democratizado por meio de exames específicos para alunos maiores de 23 anos com experiência profissional e sem percurso no sistema de ensino regular. Este texto apresenta o sistema de ensino em Portugal e destaca o impacto de Bolonha no ensino do Serviço Social. Nesse estudo de caso, aferimos que a política adotada modificou o paradigma de ensino, agora centrado na formação ao longo da vida e na valorização da experiência, e que a diminuição dos anos formativos desvalorizou a formação e a profissão do Serviço Social.
\end{abstract}

Palavras-chave: Sistema de ensino; Bolonha; Serviço social.

\begin{abstract}
:
This article aims to understand in a critical perspective the higher education in Portugal, after Bologna, showing how the social work adapted itself to this process. This change in higher education had substantial changes with respect to its configuration, access and timeliness. The training courses based on the level of degree, which in Portugal were ten semesters and passed for six or seven semesters. Access has been democratized through specific exams for students older than 23 years professional experience with and without regular courses in secondary education. This paper now presents itself situates the education system in Portugal and highlights the impact of the Bologna school of Social Work. In this case study we assess that this policy has changed the paradigm of teaching, now focused on
\end{abstract}

\footnotetext{
* Doutora em Serviço Social, docente universitária, investigadora. Universidade Lusófona de Humanidades e Tecnologias. E-mail: mariacarvalho21@hotmail.com

** Assistente social, Docente da Universidade Lusófona de Humanidades e Tecnologias. Doutoranda em Serviço Social. E-mail: helia.bracons@gmail.com

*** Assistente social, docente da Universidade Lusófona de Humanidades e Tecnologias. Doutoranda em Serviço Social. E-mail: apgmgarcia@gmail.com

**** Assistente social. Investigador da Universidade Lusófona de Humanidades e Tecnologias. E-mail: joaodanielveiga@gmail.com
} 
training and lifelong appreciation of the experience, and that the decrease in the formative years training and devalued profession of Social Work.

Key words: Education system. Bologna. Social Work.

\section{Introdução}

A formação em Serviço Social, em Portugal, tradicionalmente, efetuada em escolas específicas, foi desafiada, a partir da década de 1990, a integrar-se em universidades públicas e privadas, e a reformular seus currículos, a partir de 2000 , de acordo com os princípios da Declaração de Bolonha (DECLARAÇÃO..., 1999). Esta Declaração tem como objetivo: promover a convergência dos modelos de ensino em vários países europeus, com base em um sistema único de graus académicos facilmente reconhecíveis e comparáveis, desenvolvidos por ECTS ${ }^{1}$; qualificar a docência; e desenvolver o ensino superior numa dimensão europeia. Este modelo integrado e de convergência é baseado em três ciclos de formação superior (licenciatura, mestrado e doutoramento).

A Declaração, mais do que um conjunto de intenções, foi implementada, na maioria dos países europeus, a partir do desenvolvimento de um método aberto de coordenação (COMUNICAÇÃO..., 2002). Esta metodologia possibilitou a concretização da intenção e permitiu a uniformização do ensino e da investigação nesses países.

Esta mudança na formação académica está de acordo com os grandes pilares da estratégia europeia: educação, investigação e inovação (AGENDA..., 2000). Nesse âmbito, foram alteradas as estruturas curriculares dos cursos, agora organizadas em função da ideia de "lifelong learning", das necessidades do mercado de trabalho, do investimento na investigação, sobretudo, nos segundos e terceiros ciclos. A ideia é a de qualificação do capital humano pela investigação científica e tecnológica e da valorização da experiência de vida.

A política de democratização do ensino superior valoriza a formação ao longo da vida e as competências pessoais, sociais e profissionais adquiridas pela experiência, permitindo a certificação e o desenvolvimento de processos de capacitação e formação

\footnotetext{
${ }^{1}$ ECTS - European Credit Transfer and Accumulation System. É um sistema centrado no estudante que permite acumular e transferir créditos académicos com base na transparência dos resultados e processos de aprendizagem.
} 
através da facilitação do acesso e da frequência em cursos superiores. Uma das novidades na promoção dos princípios de Bolonha e da Estratégia de Lisboa, no que concerne à educação e à formação, tem sido a política de acesso à universidade por parte de adultos maiores de 23 anos.

Neste contexto educativo e formativo, a política de acesso à universidade propicia que alunos maiores de 23 anos, que, tradicionalmente, não chegariam ao ensino superior, experienciem, agora, a possibilidade de se inserirem numa formação superior, o que lhes permite uma integração ao processo de desenvolvimento social Europeu (PORTUGAL, 2006a). Algumas características destes estudantes podem ser identificadas: têm mais idade do que os que, tradicionalmente, buscam a formação, provenientes do sistema escolar - escolaridade obrigatória - pois muitos não a terminaram e estão afastados do sistema de ensino há alguns anos; e já têm experiência de trabalho e diversas competências profissionais, acrescidas de responsabilidades familiares (FONSECA; BAGO; SANTOS, 2011).

A integração de alunos maiores de 23 no Ensino Superior é também uma realidade quando falamos de Serviço Social. Neste âmbito, questionamos: De que modo a reestruturação do sistema educativo e a formação modificaram o Serviço Social em Portugal? Como essa alteração transformou o ensino do Serviço Social? Quais os reais impactos na vida pessoal e profissional dos alunos que frequentaram o curso pela via dos maiores de 23 anos? Quais as potencialidades e os limites que esses alunos evidenciam em relação ao ensino e à formação do Serviço Social? De que modo podem contribuir para melhorar os processos formativos nessa área?

Para responder a estas questões, partimos da tese de que a modificação da estrutura formativa dos cursos, ou seja, a diminuição do número de semestres letivos, é um factor de desvalorização do ensino do Serviço Social e, consequentemente, da profissão. Assumimos que as oportunidades de acesso ao ensino superior e a escolha da formação na área do Serviço Social representam uma forma dos sujeitos potencializarem suas competências e ajustarem-se às novas realidades sociais e económicas, adaptandose a determinadas circunstâncias da vida, cujo processo constitui um veículo para o desenvolvimento pessoal e social dos mesmos. Para que estas oportunidades se efetivem, 
são necessárias políticas de conciliação entre a vida pessoal e a vida profissional, além de metodologias específicas e conteúdos adequadas a esse tipo de alunos.

Neste contexto, analisamos: i) a política de acesso ao ensino superior desenvolvida desde 2006 em Portugal, denominada de maiores de 23 anos; ii) as transformações no ensino do Serviço Social com a alteração dos planos curriculares e com a democratização do acesso; iii) o modo como a frequência a uma formação universitária básica promoveu o desenvolvimento pessoal e social desses alunos, tendo em conta sua trajetória de vida mundo real.

Para atingir esses objetivos, caracterizamos os alunos que, ao abrigo deste programa específico, frequentaram a licenciatura em Serviço Social numa universidade na área metropolitana de Lisboa, durante os anos de 2009 a 2011, considerando várias dimensões de análise: a mudança na formação básica em Serviço Social; a motivação dos alunos para a escolha do curso; as facilidades e as dificuldades do processo; e o impacto do mesmo na vida pessoal e profissional.

Neste estudo de caso, adotamos uma metodologia quantitativa e qualitativa. Numa primeira abordagem, analisamos a base de dados dos alunos que se matricularam no curso de Serviço Social, entre 2006 e 2008, e os que o terminaram entre os anos de 2009 e 2011. Verificamos que, enquanto candidatos, eram escassos os que tinham endereço de correio eletrónico, fato essencial para o envio do questionário e da entrevista. Nessa sequência, considerámos apenas os alunos que terminaram o curso e que tinham endereço de correio electrónico².

O questionário incluía perguntas abertas, fechadas e mistas, de escolha múltipla e de escalas. Na análise dos dados quantitativos, levamos em conta a variável: sexo, idade, estado civil, nacionalidade, composição familiar, responsabilidades familiares, profissão, situação na profissão, categoria profissional, motivação para a frequência do curso (antes do acesso), dificuldades e facilidades (durante o processo) e impactos profissionais e pessoais (depois de terminado o curso). O questionário foi enviado, via correio eletrónico, para 119 alunos, obtendo-se 23 respostas válidas.

\footnotetext{
${ }^{2}$ Constatamos que alguns alunos adquiriram competências em tecnologias de informação e comunicação durante seu processo formativo.
} 
Os dados foram analisados quantitativamente com a funcionalidade de um programa estatístico adequado. Esta análise permitiu definir alguns perfis de alunos e elaborar uma entrevista semiestruturada para aprofundar seu percurso. Deste modo, depois de analisados os dados quantitativamente, foram realizadas seis entrevistas temáticas, cujos resultados foram cruzados com os dados quantitativos. Nessa análise, destacamos o impacto pessoal e social da medida de política de acesso ao ensino superior, maiores de 23 , em alunos que se matricularam no curso de Serviço Social por esta via. Este é um estudo de caso de caráter exploratório e, como tal, as conclusões obtidas não podem ser extrapoladas para outras realidades.

O artigo que agora se apresenta destaca: o surgimento e a implementação da Declaração de Bolonha no sistema de ensino universitário; sua implementação em Portugal e o modo como este teve impacto na formação do Serviço Social; e como alunos, que, tradicionalmente, não poderiam chegar à formação superior o fizeram e transformaram sua vida pessoal, familiar e profissional. Destacamos, também, o modo como o ensino, no que diz respeito à frequência ao curso, facilitou ou dificultou esse processo.

\section{Desenvolvimento social e educação ao longo da vida}

Num contexto de globalização e de transformações aceleradas, a noção de desenvolvimento fundamenta-se numa economia do conhecimento orientada para as pessoas (PORTUGAL, 2006). Neste enquadramento, o desenvolvimento social é entendido como processo onde se inter-relacionam as capacidades dos sujeitos e as possibilidades estruturais, de uma forma sustentável (SEN, 2000). A educação ao longo da vida, enquanto capital humano, é um dos pilares fundamentais para o desenvolvimento social, pois é através desta que são criadas soluções inovadoras para os problemas, tendo em conta o contexto onde se produzem.

Nesta última década, a Estratégia de Lisboa tem sido a grande referência para o desenvolvimento económico e social na União Europeia. A mesma se baseia num conhecimento dinâmico e competitivo, capaz de garantir um crescimento económico com mais empregos e, consequentemente, maior coesão (AGENDA..., 2000). Para garantir a implementação desta ideia, têm sido estabelecidas prioridades e responsabilidades, em 
todos os países ${ }^{3}$. Num contexto de crise económica, estes princípios têm sido postos em causa, pois o aumento das questões sociais são um fato, como o desemprego e os movimentos sociais.

Como já referimos, o processo de Bolonha surgiu de uma declaração conjunta de Ministros da Educação Europeus em 1999. A ideia era tornar, num único modelo, os diferentes modelos de ensino existentes (com graus académicos facilmente reconhecíveis, acumulação de créditos, mobilidade de estudantes e docentes, cooperação, aprender com a experiência) ${ }^{4}$.

Na sequência, o Conselho Europeu (COMUNICAÇÃO..., 2002) apresentou um programa de trabalho pormenorizado para a concretização de três objetivos estratégicos que apontam para a melhoria da qualidade e da eficácia dos sistemas de educação e de formação na UE, de modo a facilitar o acesso a todos os sistemas de educação e de formação e abrir ao mundo exterior os sistemas de educação e de formação ${ }^{5}$.

Concomitantemente, a Comissão das Comunidades Europeias (2003) alerta para a importância das universidades na Europa, lançando um debate sobre seu papel na sociedade e na economia do conhecimento e sobre as condições necessárias para assegurar que as mesmas possam desempenhar esse papel com eficácia. A função fundamental das universidades situa-se em três domínios: na investigação e na exploração dos seus resultados; na educação e na formação, designadamente, a dos investigadores; e no desenvolvimento regional e local, de modo a assegurar um contributo importante ${ }^{6}$.

\footnotetext{
${ }^{3}$ No caso português, destacam-se o Plano Tecnológico (2005), com referência para o programa trabalho, educação e formação, e o quadro das qualificações como tem sido até ao ano anterior a revalidação das competências.

${ }^{4}$ Esta declaração foi operacionalizada através de comunicados como o de Praga, em 2001, e o de Berlim, em 2003, no sentido de envolver as universidades e os países nestas transformações. Destaca-se também a comunicação de Bergen, em 2005, no que diz respeito ao modo de concretizar os objetivos, e a comunicação de Londres de 2007, relativamente à atenção aos desafios da globalização.

${ }^{5}$ Neste programa de trabalho pormenorizado, os três objetivos são subdivididos em treze, que refletem amplamente as áreas relacionadas com a educação e a formação. Evidencia-se as questões relacionadas com a aquisição de novas competências essenciais: as tecnologias da informação, a matemática, as ciências e a tecnologia.

${ }^{6}$ Nesta linha de análise, a União Europeia defende uma comunidade universitária sólida e próspera. A Europa necessita de excelência nas suas universidades, para que torne a economia, baseada no conhecimento, mais dinâmica e competitiva no mundo, capaz de garantir um crescimento económico sustentável, com mais e melhores empregos e com maior coesão social. É referido que as universidades trabalham num ambiente cada vez mais globalizado e em constante evolução, marcado por uma concorrência para atrair e manter os melhores talentos, responder às novas necessidades e das quais têm
} 
Nessa comunicação, é referido, ainda, de forma geral, que as universidades estão no centro da Europa do conhecimento, pois combinam quatro elementos importantes: a produção do conhecimento pela investigação científica; sua transmissão por meio da educação e da formação; sua divulgação com base nas tecnologias da informação e da comunicação; e sua exploração através da inovação tecnológica (COMISSÃO DAS COMUNIDADES EUROPEIAS, 2003). As universidades contribuem também para a realização de alguns objetivos focados na Estratégia de Lisboa (AGENDA..., 2000), designadamente, o emprego e a coesão social, bem como, a melhoria do nível geral da educação na Europa.

As universidades são, atualmente, confrontadas com mudanças e novos desafios que exigem adaptação, devido aos seguintes fatores: o crescimento da procura por formação superior; internacionalização da educação e da investigação; estabelecimento de uma relação estreita e eficaz entre universidades e empresas; multiplicação dos lugares de produção de conhecimentos; reorganização do conhecimento; e surgimento de novas expectativas ${ }^{7}$. O ensino do Serviço Social, assim como de outras áreas disciplinares e profissionais, integrara a formação com base nesse modelo.

A União Europeia (PORTUGAL, 2006c, p. 2) tem reforçado: a importância da aprendizagem ao longo da vida e a mobilidade; a melhoria da qualidade da eficácia e da formação; a igualdade e a coesão social; e a cidadania ativa, assim como, o incentivo à criatividade e à inovação, incluindo o espírito empreendedor em todos os níveis. Neste documento (PORTUGAL, 2006c), destacam-se algumas recomendações aos Estados Membros, no que diz respeito à aquisição de competências essenciais para a aprendizagem ao longo da vida.

\footnotetext{
que dar resposta. Alerta para o facto de que por vezes de as universidades europeias têm geralmente menos para oferecer e dispõem de menos meios financeiros do que os outros países desenvolvidos. E por estes fatores, é interpelado a todos os intervenientes no domínio do ensino superior, da investigação e da inovação a transmitirem os seus pontos de vista, comentários, sugestões sobre os aspectos abordados na comunicação, para que se possa definir futuras linhas de ação.

7 Uma das preocupações da Comissão (2005a), é converter as universidades europeias numa referência a nível internacional. Para que isso aconteça as universidades devem responder a novos e diversos desafios e alcançar três objetivos: garantir que as universidades disponham de recursos suficientes e sustentáveis e que os utilizem com eficácia; reforçar a sua excelência, tanto em matéria de investigação como de ensino, pela criação de redes e assegurar uma maior abertura das universidades para o exterior e tornálas mais atractivas no plano internacional.
} 
Este documento salienta a importância das competências essenciais para a aprendizagem ao longo da vida no quadro de referência europeu, considerando a importância dos seguintes objetivos: identificar e definir as competências essenciais necessárias à realização pessoal, à cidadania ativa, à coesão social e à empregabilidade na sociedade do conhecimento; apoiar os trabalhos dos Estados Membros destinados a garantir que os jovens adquiram um domínio das competências essenciais para que estejam preparados com uma uma boa base para a aprendizagem futura; proporcionar aos decisores políticos, professores, um instrumento de referência, em nível da Europa, destinado a apoiar os esforços, no âmbito nacional e europeu, para atingir os objetivos acordados e, por fim, constituir um quadro para a ação futura em nível comunitário ${ }^{8}$.

Nas conclusões do Conselho Europeu de 2009, relativas ao quadro estratégico para a cooperação europeia no domínio da educação e da formação, é sublinhado que estas têm um papel crucial a desempenhar face aos desafios que se colocam para a Europa e seus cidadãos, ou seja, que é necessário investir em capital humano por meio desses sistemas. A educação e a formação constituem duas componentes essenciais da estratégia adotada para se atingir os elevados níveis de crescimento e emprego baseados no conhecimento, promovendo a realização pessoal, a coesão social e a cidadania ativa.

Em tempo de grave crise económica, a União Europeia destaca a educação e a formação como pilares fundamentais para o enfrentamento do desafio socioeconómico, demográfico, ambiental e tecnológico. A comunicação de Leuven, de 2009, dos ministros da educação da União Europeia, analisa a implementação do processo, nesse contexto, destacando os desafios da década vindoura.

Atualmente, a Estratégia Europeia 2020 (EUROPEAN UNION, 2010) para o desenvolvimento económico e social em tempo de crise financeira reflete sobre o

8 O texto faz ainda referência às competências essenciais, definidas como uma combinação de conhecimentos, aptidões e atitudes adequadas ao contexto, salienta que as competências essenciais são aquelas que são necessárias a todas as pessoas para a realização e o desenvolvimento pessoais, para exercerem uma cidadania ativa, para a inclusão social e para o emprego. As competências essenciais mencionadas contribuem para uma vida bem-sucedida na sociedade do conhecimento. Possuir as competências básicas fundamentais é uma condição essencial para "aprender a aprender". Neste quadro de referência e de análise são identificadas algumas competências, tais como a: comunicação na língua materna; comunicação em língua estrangeira; competência matemática e competências básicas em ciência e tecnologia; competência digital; aprender a aprender; competências sociais e cívicas; espírito de iniciativa e espírito empresarial e, sensibilidade e expressão cultural. Os temas que fazem parte do referido texto, como elementos essenciais são: pensamento crítico, criatividade, espírito de iniciativa, resolução de problemas, avaliação de riscos, tomada de decisões e a gestão construtiva dos sentimentos. 
percurso do desenvolvimento sustentável e enfatiza a ideia de que, mesmo em crise, a Europa não pode se esquecer de investir na educação e na formação ao longo da vida, para a promoção do crescimento económico e da inovação ${ }^{9}$.

A cooperação europeia a ser desenvolvida até 2020 , no domínio da educação e da formação, é desafiada a ser integrada no âmbito de um quadro estratégico, onde a aprendizagem ao longo da vida deve ser considerada como um princípio fundamental subjacente a todo o quadro, que deve incluir a aprendizagem em todos os contextos e em todos os níveis. Nesse enquadramento, são identificados quatro objetivos estratégicos: tornar a aprendizagem ao longo da vida e a mobilidade uma realidade; melhorar a qualidade e a eficácia da educação e da formação; e promover a igualdade, a coesão social e a cidadania ativa e incentivar a criatividade e a inovação, incluindo um espírito empreendedor. Apesar da bondade da ideia e do espírito integrador da política - ensino, formação, investigação, inovação - esta foi e é alvo de muitas críticas e resistências na sua aplicação em Portugal.

Em suma, a implementação do processo de Bolonha trouxe consigo a democratização do ensino superior em países Europeus, nomeadamente, em Portugal, modificando o paradigma de ensino superior direcionado a elites, para um ensino superior de massas. Embora a educação seja um bem de natureza coletiva (DELORS, 1996), esta generalização impôs novos desafios à educação e ao sistema educativo. O percurso de transformação e de implementação de novas políticas divergiu nos diferentes países da Europa, embora se verifique, cada vez mais, convergência, particularmente, em nível dos programas de estudo e do sistema de graus académicos (FERREIRA, 2007).

\section{Transformações no sistema de ensino superior em Portugal}

Em Portugal, desde 2006, tem sido implementado o processo de Bolonha. Alguns decretos de lei foram fundamentais e indispensáveis para a implementação desta nova via de ensino superior. Um desses decretos diz respeito à lei de bases do sistema educativo - Lei no 49/2005 (Esta consagra o direito ao acesso ao ensino superior, por

\footnotetext{
${ }^{9}$ Neste contexto a declaração de Budapeste dos Ministros da Educação Europeus (12 de Março de 2010) destaca a liberdade académica que pode estar a ser posta em causa neste contexto de crise e enfatizam a responsabilidade pública dos estados pelo ensino superior.
} 
meio de provas de capacidade, a indivíduos que não estão habilitados com curso secundário ou equivalente) (PORTUGAL, 2005).

O Decreto de Lei n. 64/2006, do XVII Governo Constitucional, promulgado em 1 de Março de 2006, entrou em vigor no ano letivo 2006-2007, acompanha estas alterações e estabelece as condições especiais de acesso ao ensino superior para maiores de 23 anos. Este Decreto permite uma igualdade de oportunidades de acesso ao ensino superior, com exceção dos estabelecimentos de ensino superior público, militar e policial, a todos aqueles com idade igual ou superior a 23 anos, desde que, mesmo não possuindo as habilitações necessárias, ou seja, o ensino secundário ou o equivalente completo para o ingresso no ensino superior, façam uma prova, especialmente adequada, de capacidade para sua frequência. Permite-se, assim, um maior recrutamento de eventuais candidatos, possibilitando o ingresso, no ensino superior, de estudantes adultos (PORTUGAL, 2006a).

A mesma lei (PORTUGAL, 2006a) valoriza os conhecimentos, a experiência, o desenvolvimento pessoal e social e toda a aprendizagem adquirida ao longo da vida. A responsabilidade pela seleção dos alunos adultos é das respectivas instituições de ensino superior, por meio de provas realizadas anualmente, que visam a valiar a capacidade para a frequência de um curso de licenciatura. A avaliação do currículo escolar e profissional e do perfil e das suas motivações do candidato é realizada por meio de uma entrevista e de provas teóricas e práticas, com o objetivo de se analisar as competências e conhecimentos indispensáveis ao ingresso e progressão no curso, que pode ser organizado em função dos diferentes perfis dos candidatos e dos cursos a que estes se candidatam. A organização e a realização das provas são da competência de júris nomeados também pela respectiva instituição de ensino superior a que o aluno se candidata.

O Decreto de Lei nำ74/2006, aprovado em 16 de Fevereiro de 2006 e promulgado em 20 de Março de 2006, também procede à regulamentação das alterações introduzidas pela Lei de Bases do Sistema Educativo ${ }^{10}$ relativas ao novo modelo de organização do

\footnotetext{
${ }^{10}$ Esta lei encontra-se estruturada em cinco títulos principais: os graus académicos e diplomas do ensino superior (título II); aos princípios gerais a que se subordina o processo de acreditação (título III); as regras a aplicar para a reorganização dos cursos em funcionamento (título IV); as regras transitórias a adoptar para a criação de novos ciclos de estudos até à criação e entrada em funcionamento da agência de acreditação (título V); as regras a adoptar param o registo de alterações, designadamente das referentes aos planos de estudos dos cursos e por último (título VI) a caracterização mais detalhada de cada um dos
} 
ensino superior, no que diz respeito aos três ciclos de estudos (Licenciatura, com uma duração compreendida entre seis a oito semestres; Mestrado, com uma duração entre três e quatro semestres e, por fim, o Doutoramento). Cada ciclo é estruturado de acordo com o sistema europeu de créditos curriculares e visa à passagem de um sistema de ensino baseado na ideia da transmissão de conhecimentos para um sistema fundamentado no desenvolvimento de competências e na promoção da mobilidade e da competitividade profissional (PORTUGAL, 2006b).

Ao contrário de outras formações, como a psicologia, a arquitetura, a medicina, o direito e algumas engenharias, que optaram por mestrado integrado, isto é, uma formação integrada de cinco anos, que atribui o grau de licenciado (três anos) e o grau de mestre (5 anos), a comissão responsável pela adequação de Bolonha, em Portugal, adotou outro princípio para as ciências sociais e humanas: os cursos das ciências sociais deveriam funcionar com o modelo tripartido - licenciaturas, mestrado e doutoramento em separado. Este modelo afetou, significativamente, o ensino e a formação do Serviço Social em Portugal. Tradicionalmente, a formação do Serviço Social, em Portugal, era de 4 anos, passando a ser, na década de 1990, de cinco anos. Desta forma, a formação foi "obrigada"11" a reduzir os anos formativos e a promover mestrados e doutoramentos em programas separados ${ }^{12}$. A seguir, será apresentada, de forma mais substantiva, o modo como esse processo transformou o ensino do Serviço Social em Portugal.

\section{Adequação do serviço social a Bolonha}

Em Serviço Social, a formação ao longo da vida é condição fundamental para o desenvolvimento das práticas e do conhecimento em uma realidade em constante mutação. Como considera Payne (2005), a educação em Serviço Social não termina com a obtenção de graus académicos, pois este é o ponto de partida para o desenvolvimento da aprendizagem. Esta é uma das especificidades das profissões que se centram na "ajuda às

três ciclos de estudos no quadro dos trabalhos desenvolvidos no âmbito do Processo de Bolonha. São estas as principais medidas de política pública quando falamos do acesso ao ensino superior pela via dos "maiores de 23 anos".

11 A palavra "obrigada" e utilizada evidenciar o desagrado dos assistentes sociais com esta mudança. Qualquer área formativa que implique seres humanos requer uma formação base mais substantiva para potenciar reflexões substantivas sobre as questões sociais em presença.

12 Por exemplo em Espanha o processo foi inverso. Cursos de Trabalho Social que antes de Bolonha eram de 3 anos passaram a ser depois de Bolonha de 4 anos. 
pessoas". Segundo o mesmo autor, a aprendizagem em Serviço Social faz-se: pela experiência reflexiva do trabalho de campo em organizações específicas; com outros profissionais; e com formação especializada em exercício e com a articulação desses saberes com a formação graduada em nível de mestrado e doutoramento. O objetivo é o desenvolvimento social e pessoal, como algo em "devir".

Nesta linha de análise e tendo em conta a especificidade desta formação, as universidades, escolas e institutos que oferecem cursos de Serviço Social, em Portugal, foram desafiadas, pela comunidade e pelas organizações onde os assistentes sociais desenvolvem a ação profissional, num duplo sentido: qualificar suas práticas e melhorar os serviços e a intervenção junto à população. Como responder a estes desafios? Pelo desenvolvimento de ações de formação em articulação com as organizações e os profissionais e pela potencialização da investigação nesta área, dando visibilidade às realidades sociais.

Antes mesmo da institucionalização da profissão, já existia uma preocupação com a formação na área do Serviço Social (MARTINS, 1999). A década de trinta, do século vinte, marca o início da formação em Serviço Social em nosso país ${ }^{13}$ (BRANCO, 2009a, 2009b, 2009c; MARTINS, 1999). De 1935 a 1995, a formação em Serviço Social esteva a cargo de três escolas específicas, que formavam assistentes sociais - os Institutos Superiores de Serviço Social de Lisboa, de Coimbra e do Porto.

A partir de 1995, o Serviço Social inseriu-se em universidades públicas, privadas e do ensino concordatário, e em institutos e escolas superiores, públicas e privadas (BRANCO, 2009a, b; BRANCO; FERNANDES, 2013), assistindo-se, asim, a um aumento do número de cursos, que passaram de 3 para $22{ }^{14}$ (BRANCO, 2009c).

Como já referimos, a educação superior, que, até 2006, privilegiava a formação base de 4/5 anos, passou, desde então, a ser de 3 e de 3 anos e meio. A formação especializada foi disseminada com mestrados, quer em Serviço Social, quer em áreas de intervenção associadas à infância em risco e perigo, à gerontologia, à saúde, às psicoterapias e à gestão. Para além desta oferta formativa pós-graduada, foram também

\footnotetext{
${ }^{13}$ A institucionalização da formação deu-se a par com o desenvolvimento de escolas de Serviço Social noutros países (MARQUES; MOURO, 2004; MOURO; SIMÕES, 2001).

${ }^{14}$ Em 2012 registamos 25 cursos de Serviço Social.
} 
criados programas de formação avançada com doutoramentos em universidades públicas, privadas e do ensino concordatário (Universidade Católica).

Esta transformação no ensino foi cruzada com um investimento em políticas sociais, sobretudo, pelos governos socialistas, com destaque para: a introdução do rendimento social de inserção; a rede de cuidados continuados integrados; a melhoria e a difusão de respostas para idosos; e a criação de comissões de proteção a crianças e jovens, para enunciar aquelas que empregaram mais profissionais de Serviço Social, quer em organizações públicas, quer em privadas não lucrativas (BRANCO, 2009 a, b; CARVALHO, 2010).

A aprendizagem "da prática" "na prática" profissional é um processo inerente ao próprio Serviço Social, assim como a dimensão investigativa, contudo, esta última nunca teve grande impacto, nem na academia nem na intervenção. Na década de 1960, foram introduzidas, na formação, metodologias de investigação científica (BRANCO, 2008). Entretanto, foi no final dos anos de 1980 que se consagrou este tipo de procedimento, de forma sistemática, no ensino e na formação, com a aprovação da licenciatura em Serviço Social em 1989 - cinco anos. O plano de estudo integrava a realização de um trabalho de pesquisa no último ano do curso. Esta metodologia, orientada para a investigação, valorizou o conhecimento, a profissão e o ensino do Serviço Social. A melhoria na qualificação possibilitou, cada vez mais, práticas teoricamente orientadas em políticas denominadas ativas.

O processo de Bolonha vem valorizar a investigação e o conhecimento adquirido por meio do "aprender fazendo" e também do "aprender com os outros". Este conhecimento, implícito na formação e na profissão do Serviço Social, ganhou uma visibilidade até então nunca experimentada. Apesar dessa melhoria quantitativa e qualitativa neste domínio, verifica-se que a pesquisa ainda fica aquém do desejado e que predominam práticas pouco sustentadas em nível teórico - research-oriented ${ }^{15}$.

\footnotetext{
${ }^{15}$ Nesta linha de análise Branco (2008), enuncia algumas dificuldades para o desenvolvimento da investigação em Serviço Social em Portugal i) Peso das atribuições sócio-institucionais do Serviço Social; ii) a cultura e habitus profissional, pautados pelo predomínio da acção em detrimento do conhecimento, em boa parte resultado da socialização profissional gerada pelo processo sócio-histórico de desenvolvimento e exercício profissional, consolidar-se-ia em traços identitários como o pragmatismo e a acomodação e por último a iii) insuficiente formação de pesquisadores.
} 
Bolonha desafiou então o Serviço Social para: a criação de estruturas permanentes de investigação no contexto académico e profissional, no sentido de ir além das investigações nos mestrados e doutoramentos; o reconhecimento do Serviço Social como área de produção de conhecimento pelas agências de apoio e financiamento da investigação social; e a adoção de políticas e dispositivos de difusão e intercâmbio da pesquisa nesta área (FALEIROS, 1997; MARTINS, 1999).

Para que o conhecimento do Serviço Social se enquadre nesse modelo, Branco (2008) propõe: a articulação de um conjunto de condições, principalmente de natureza sócio-institucional, para o desenvolvimento académico do Serviço Social, com base no reconhecimento universitário da formação e da investigação, na criação e implementação da formação pós-graduada, em nível de mestrado e doutoramento, e na melhoria do ensino e da formação para a investigação no quadro da formação-base e pós-graduada.

Outras questões também têm sido fonte de preocupação, nomeadamente, a desvalorização da formação de base, pois o processo tornou a formação inicial mais curta e esta foi introduzida em universidades e institutos que, tradicionalmente, não ofereciam formação nesta área. Efetivamente, alguns cursos funcionam sem nenhum docente com formação em Serviço Social (MARTINS, 2008) e a maioria destes é coordenada por pessoas com outras formações académicas. Também a questão da empregabilidade dos profissionais constitui um fator de preocupação, pois, com a massificação da formação, nem todos têm lugar no mercado de serviços (MARTINS; TOMÉ, 2008).

Apesar de o Serviço Social, em nosso país, ter mais de meio século, muito ainda há a fazer para a construção de um corpo de saber específico e de uma cultura profissional que defenda, por um lado, a especificidade do saber em Serviço Social, e, por outro, a abertura suficiente a outras disciplinas enquanto complemento multidisciplinar. Assim, é necessário que o Serviço Social tenha a capacidade de "fechamento" para criar um corpo de saber específico e uma abertura disciplinar, de modo que, numa relação articulada e complementar, consiga uma melhor compreensão dos fenómenos sociais do mundo da vida e dos sistemas. Os resultados dos dados recolhidos no estudo de caso (universidade/Serviço Social) são apresentados a seguir. 


\section{O ensino do serviço social - formação de alunos maiores de 23 anos}

Perfil dos alunos

Os alunos que chegaram ao curso de Serviço Social por essa via são, majoritariamente, do sexo feminino, 20 do total (87\%), e somente 3 do sexo masculino (13\%). Esta tendência está de acordo com a realidade da profissão em relação ao gênero, já que é uma profissão ainda, essencialmente, feminina. As idades situam-se entre os 26 e os 56 anos, distribuídas pelas seguintes faixas etárias: entre os 26 e os 30 anos, 7 alunos (30\%); entre os 31 e os 40 anos, 6 alunos (26\%); entre os 41 e os 50 anos, 8 alunos (35\%); e entre os 51 e os 60 anos, 2 alunos (9\%).

Quanto ao estado civil, existe uma predominância para o estado de solteiros (as), em 13 do total (57\%); 7 casados (as) (30\%); e 3 divorciados (as) (13\%). Dentre os pesquisados, 10 (43\%) vivem com o marido/mulher e ou companheiro e 8 (35\%) vivem só. Entre os casados, 5 (22\%) vivem com os filhos adolescentes; 4 (4\%) com filhos com menos de 6 anos e com filhos adultos, em cada item; 3 (13\%) com filhos entre 6 e 12 anos; e 1 (4\%) com esposa/companheiro e com pais idosos, em cada item.

A escolaridade, antes do acesso ao ensino superior, era de ensino secundário incompleto, para $10(43 \%)$ dos participantes, e de ensino secundário completo, sem exame de acesso ao ensino, também para 10 (43\%) deles, seguindo-se do ensino básico, até o 9o ano, para 2 (9\%), e outro grau acadêmico, em nível técnico profissional, para outros 2 (9\%). A profissão exercida é, predominantemente, no setor dos serviços das profissões não qualificadas, destacando-se a de auxiliar de serviços gerais e técnicos administrativos. Dos inquiridos, 15 (65\%) tinham uma situação profissional estável, com contrato de trabalho; 2 (9\%) eram profissionais liberais; 4 (17\%), desempregados; e 4 (17\%) apresentavam outras situações. Os anos de exercício profissional variam entre nenhum ano e 25 anos. Esses alunos são, majoritariamente, de nacionalidade portuguesa, mas também de outros países europeus, destacando-se, contudo, os naturais de países africanos e da América do Sul. Estes dados estão de acordo com o estudo de Gonçalves et al. (2011), que revela que esses candidatos têm mais idade do que os que, tradicionalmente, entram no ensino superior, além de terem responsabilidades familiares e já exercerem uma profissão. 


\section{Motivação para o acesso ao ensino superior}

Situado o perfil dos alunos que frequentaram o curso de Serviço Social pela via dos maiores de 23 anos, nos anos pesquisados, analisamos o que os impulsionou a frequentar o ensino superior. Neste item, destacaram-se três aspectos: a valorização pessoal para 15 (65\%) deles; mudar de vida pessoal e profissional, para 13 (57\%); ter competência para ajudar os outros e ter experiência de trabalho na ação social, para 9 (39\%). Identificamos, ainda, um conjunto de motivos, tais como: mudar de emprego, subir na carreira profissional e gostar de estudar, com 7 (30\%); ter mais tempo para estudar e outras situações, com 4 (17\%); ter sido apoiado por uma assistente social, com 2 (9\%); e, por último, viver perto da universidade, com 1 (4\%).

As motivações para a escolha do curso são várias e situam-se: em nível micro, questões pessoais; em nível meso, trabalho e família; e em nível macro, relacionadas a princípios e valores universais globais, evidenciando-se estas últimas na motivação para a escolha do curso.

Os motivos que se destacaram foram os seguintes: ser defensor da solidariedade e do bem-estar, com 21 (91\%); defender os direitos humanos, com 20 (87\%); gostar de ajudar os outros e ter apetência para o desenvolvimento social, com 19 (83\%) cada; e escolheu o curso por este estar associado à justiça social, com 9 (39\%). Os motivos que se destacaram estão de acordo com princípios que os alunos associam à profissão, nomeadamente, os da dignidade humana, empowerment e capacitação, com 20 (87\%); e a promoção dos direitos humanos e defesa dos grupos mais vulneráveis, com 17 (74\%).

Ainda no que diz respeito à motivação para a escolha do curso, os itens menos valorizados foram: ter um familiar que é assistente social e conhecer um assistente social fora do contexto familiar, que Ihe indicou o curso, com 1 (4\%); indicações de amigos ou familiares e/ou já ter tido apoio social, com 3 (13\%); e trabalhar na área, com 4 (17\%). Nas motivações, destacamos o discurso sobre a experiência profissional na área da ação social e a informação acerca da mudança da política de acesso à Universidade. Segundo alguns entrevistados:

Ter integrado durante 10 anos um projeto de intervenção comunitária no âmbito do Programa de Luta Contra a Pobreza (E3). Também a experiência de 
acompanhamento dos clientes que dirigem aos serviços e que requereu um maior saber na área para uma ajuda centrada na lei e nas necessidades de cada um (E4). Também o facto de ter conhecimento prévio acerca da mudança da política de acesso à Universidade: [...] desde que fiquei a saber do Bolonha, o meu sonho era entrar para universidade (E5). E desta forma quando soube desta oportunidade não hesitei e realizei os exames de admissão (E2).

\section{Frequência do curso de Serviço Social}

Durante a frequência do curso, 5 (22\%) dos inquiridos tiveram acesso à certificação de competências e 3 (13\%), a equivalências. Contudo, 13 (57\%) deles referem que não a tiveram e sublinham que a formação foi idêntica à dos alunos que concluíram o curso pela via normal de acesso ao ensino superior. Este aspecto é muito importante, pois, nesse processo de ensino, posicionam-se diferentes percursos escolares. Estas diferenças no percurso escolar requerem metodologias diversificadas, como, por exemplo, currículos alternativos com a inclusão de língua portuguesa e inglesa, escrita, planeamento do estudo, investimento em tutorias, entre outros aspectos. Algumas destas não estão previstas e os alunos não usufruíram das mesmas.

Para além da qualificação das competências, o apoio familiar revelou-se importante para o prosseguimento dos estudos, para 17 inquiridos (74\%). Este aspecto reveste-se da maior importância, pois uma política de ensino, ao modificar as condições de acesso, também tem que prever e desenvolver outras políticas compatíveis com a concretização das motivações, nomeadamente, criando oportunidades de estudo nas empresas e favorecendo a conciliação da vida profissional e pessoal. Neste sentido, as motivações e o esforço pessoal têm um destaque acrescido:

Para a conclusão do curso não só contribuiu o meu empenho e esforço, bem como o empenho da família, a qual sofreu algumas alterações nas dinâmicas familiares, pois como tinha de me deslocar todos os dias para Lisboa, isso implicava que o meu marido assumisse por completo o apoio aos filhos e parte da gestão da casa (E1).

Na falta de uma organização curricular adequada para estes alunos, os professores surgem como as pessoas que mais os apoiaram durante a frequência ao curso, no que diz respeito à adequação das metodologias para o desenvolvimento das competências requeridas: "Considero relevante mencionar o bom apoio que tive sempre por parte do corpo docente, que as metodologias seguidas foram de encontro ao que eu esperava $e$ 
que hoje se tenho a prática que tenho devo-o à teoria que me foi incutida ao longo do curso" (E1).

No processo de aprendizagem, as unidades curriculares de estágios académicos apresentam-se como as que propiciaram o desenvolvimento de um maior número de aptidões, seguindo-se as unidades de seminários, as unidades teóricas e práticas do Serviço Social e as das ciências sociais humanas.

Durante o curso, algumas mudanças pessoais e familiares foram acontecendo. As que mais se destacaram foram: situações de doença, 7 (30\%); desemprego, 4 (17\%); mudança de residência, 4 (17\%); nascimento de filhos, 3 (13\%); falecimento de um membro da família; 2 (9\%); e casamento 1 (4\%). Entre as mudanças no âmbito do emprego, destacam-se: mudança de empresa, 7 (30\%); desemprego, 6 (26\%); outra função mais valorizada 4 (17\%); e a despromoção, 1 (4\%). Algumas questões destacam-se: "No início tive alguma dificuldade em me organizar quer a nível de estudo quer a nível de trabalho, uma vez que as aulas tinham início às 18 horas, o que na minha opinião está desajustado aos horários de trabalho" (E2).

O dia-a-dia tornou-se mais sobrecarregado mais exigente para a família e para conseguir conciliar todos os parâmetros [...] porque todos dependiam de mim e do que deixasse estruturado, numa continuidade mais fácil, quando chegasse. Também a nível de emprego existiu essa mudança devido á falta de aceitação da chefia que tentou o impedimento (E4).

\section{Impacto da frequência do ensino superior e do curso de Serviço Social}

Depois de analisadas algumas questões face ao acesso e à frequência ao curso, verificámos que 15 (65\%) inquiridos terminaram o curso em três anos; 3 (13\%) inquiridos terminaram o curso em 4 anos; e 5 (22\%) ainda o frequentam. As habilitações literárias atuais são: para 14 (61\%), a licenciatura; a frequência de mestrado, para 5 (22\%); e para 1 (4\%), a pós-graduação.

Quanto ao impacto da frequência ao curso na vida pessoal, profissional e familiar, destaca-se a ideia de que "frequentar a universidade foi a melhor coisa que já fez" e o impacto no "aumento da sua auto-estima". Consideram também que "são um exemplo a seguir pois esteve muitos anos sem estudar". Com menos impacto, estão as questões familiares, não existindo aspectos negativos a considerar. 
A ideia que prevalece é a de empenho, esforço e reconhecimento da família pelo mesmo: "Sei que este meu esforço foi acolhido pela minha família com orgulho, o da mãe ter conseguido, afinal nada na vida é fácil" (E2).

A frequência ao curso possibilitou aos inquiridos: exercer as funções de assistente social, para 6 (26\%); e para 2 (9\%), possibilitou a mudança para um emprego mais adequado às suas qualificações. Apesar de tudo, 8 (35\%) conseguiram exercer uma profissão mais qualificada e a profissão de Assistente Social.

A conclusão da licenciatura em primeira mão trouxe-me uma grande satisfação a nivel pessoal e, claro será dizer que também teve impacto na questão profissional, dado que logo que terminei o curso e me candidatei a estágio profissional e com a experiência que já tinha anterior, foi um trampolim para estar a fazer e na qualidade de Técnica Superior, o que hoje faço (E1).

Para 12 (52\%) dos pesquisados, esta última circunstância ainda não se verificou, e 3 (13\%) não responderam, porque ainda frequentam o ensino. Os que se mantêm na atividade profissional anterior, é porque ainda não ocorreram alterações na situação profissional, no entanto, este facto não é motivo para que os mesmos percam a motivação de exercer futuramente a profissão.

É minha intenção continuar/voltar a estudar, pelo menos tirar o grau de mestre, se possível na área da lgualdade de Género ou em violência doméstica. Tal ainda não foi feito porque tenho atualmente dois filhos a terminar o ensino superior e não é possível conciliar economicamente os três estudarem (E1). Terminei o curso e estou a pensar tirar uma pós graduação (E2).

Alguns, apesar de não exerceram a profissão, definem estratégias para o exercício da mesma:

Como gosto da ação social e como podia doar algum do meu tempo uma vez que a minha situação familiar me permitia não hesitei em ser voluntária da Instituição na qualidade de Assistente Social, assumindo todos os deveres da profissão e da Instituição e abdicando dos direitos inerentes a elas. Sendo certo que só é possível esta minha colaboração especializada nesta instituição porque tive a oportunidade de adquirir os conhecimentos superiores nesta fase da vida já adulta. A ação social sempre foi para mim impulsionadora, mas só caritativa não, agora sim estou potenciada para ajudar mas sobretudo capacitada para a mudança, valorizar, dignificar a pessoa como um todo na sua dimensão Humana (E2).

No que diz respeito à formação, os entrevistados consideram que, se a formaçãobase fosse mais longa, valorizaria a profissão de assistente social. Assim, a formação de 
base deveria ser mais longa em termos de semestres e ou de cariz integrado, tal como nos indica a entrevistada "prolongar a licenciatura com mais um semestre ou então com mestrado integrado" (E3).

Em síntese, tal como outros cursos superiores, o Serviço Social possibilita que pessoas com trajetórias diferenciadas, no sistema escolar, integrem a formação superior e transformem sua vida pessoal e social. Contudo, podemos identificar algumas características levantadas neste estudo de caso.

A feminização da profissão é um facto, pois os alunos que frequentam o curso são, sobretudo, mulheres. Estas se destacam por: se encontrarem em idades situadas entre os quarenta e os cinquenta anos; e serem solteiras e viverem com um companheiro. Estas últimas vivem com filhos na idade da adolescência. A maioria não tem o ensino secundário completo; a profissão que exerce é não qualificada, mas a situação profissional é estável. Os alunos optam por frequentar o ensino superior por uma questão de valorização pessoal, mais do que por uma questão de valorização profissional ou familiar, apesar destas estarem interligadas. Esta constatação é confirmada quando os inquiridos identificam que a frequência ao curso aumentou sua autoestima. Os candidatos manifestam sensibilidade face a valores da solidariedade dos direitos humanos orientados para o desenvolvimento social. Estas são as principais razões para a escolha do curso. É sem dúvida uma das mais-valias da mudança na política de Bolonha em relação ao ao curso de Serviço Social, pois possibilita que mulheres com diferentes trajetórias se capacitem e empoderem.

Identificámos, ainda, outros aspectos, nomeadamente: a redução dos anos de formação; o currículo idêntico ao dos outros alunos que frequentam o ensino regular; e a não existência de metodologias específicas que levam em conta a trajetória escolar e profissional. Verificámos, também, que, durante o percurso formativo, foi a família que mais apoiou os alunos nesse processo, sendo necessário acionar políticas mais efetivas de conciliação do trabalho com o estudo e com a formação ao longo da vida. A crise econômica e financeira e a escassez do emprego impedem que a maioria exerça a profissão do Serviço Social. 


\section{Para concluir}

Nestes últimos anos, assistimos a uma transformação sem precedentes no sistema de ensino superior em Portugal. De um modelo tradicional de formação, centrado na transmissão de conhecimentos, Bolonha veio propor um novo paradigma de ensino que, como refere Ferreira (2007), supõe mudanças que vão do modelo educativo e organizacional, aos objetivos e à própria avaliação. As orientações de Bolonha propõem uma perspetiva integrada com valorização da aprendizagem e da formação ao longo da vida, com aquisição de graus académicos. As universidades foram chamadas a contribuir para o modelo de desenvolvimento social europeu, baseado no capital humano, de modo a estimular o aperfeiçoamento humano e diminuir as desigualdades sociais.

Portugal participou e integrou essas medidas a partir de 2006. Essa transformação desafiou a formação em Serviço Social orientada para um público-alvo com perfis diversos, incluindo alunos com mais idade e com mais experiência profissional. Neste estudo exploratório, a ideia inicial de que a oportunidade de frequentar o ensino superior, por parte de alunos com 23 anos ou mais, potencializa motivações pessoais e transformações substantivas na vida dessas pessoas, confirmou-se.

Contudo, o processo de Bolonha e o acesso de alunos ao ensino superior em função da idade não foi, nem é pacífico, e, claramente, desvalorizou a formação-base em Serviço Social. Pudemos concluir que este processo de formação tripartido (licenciatura (3 anos) e mestrado (2 anos) e doutoramento (3 anos) - desvalorizou a formação-base e graduada em Serviço Social. A formação-base, por não ser obrigatória e ser desenvolvida de uma forma integrada (mestrado integrado em serviço social com duração de cinco anos), posicionou a profissão do serviço social em desvantagens no mercado de trabalho, face a outras formações que adotaram este modelo, como é o caso da psicologia.

É certo que a formação-base não pode ser um fim em si mesma. Entretanto, uma boa formação inicial, com tempo de maturação, que reforce a capacidade de reflexão sobre as questões sociais, é essencial para se evoluir no conhecimento e no exercício da actividade, numa profissão como o Serviço Social. Para que a profissão possa se consolidar na academia e no mercado de trabalho, defendemos que, neste contexto de mudança do paradigma educativo, o serviço social adote uma formação integrada - 
licenciatura com mestrado (cinco anos) - e, posteriormente, o acesso a doutoramentos e pós doutoramentos.

\section{Referências}

AGENDA de Lisboa: estratégia de Lisboa. Lisboa, 2000.

BRANCO, F. A investigação em serviço social em Portugal: trajectórias e perspectivas. Revista Locus SOCl@L, Lisboa, v. 1, p. 48-63, 2008.

A profissão de assistente social em Portugal, breve perspetiva histórica e análise curricular da formação superior em Serviço Social pos-reforma de Bolonha. 2009c. Disponível em: <http://www.cesssucp.com.pt/papers/files/Branco_WorkPaper_01_2009.pdf>. Acesso em: 14 mar. 2012. . A profissão de assistente social em Portugal. Revista Locus SOCl@L, Lisboa, n. 3, p. 61-89, 2009a.

Assistentes sociais e profissões sociais em Portugal: notas sobre um itenerário de pesquisa. Revista Locus SOCI@L, Lisboa, v. 3, p. 7-19, 2009 b.

BRANCO, F.; FERNANDES, E. O serviço social em Portugal: trajectória e encruzilhada. Disponível em: <www.CPIHTS.com>. Acesso em: 5 jul. 2013.

CARVALHO, M. I. L. B. Serviço social em Portugal: percurso cruzado entre a assistência e os direitos. Revista Serviço Social\& Saúde, Campinas, n. 10, v. 10, p. 30-47, 2010.

COMISSÃO DAS COMUNIDADES EUROPEIAS. O papel das universidades na Europa do conhecimento. Bruxelas, 2003.

COMUNICAÇÃO do Conselho Europeu: programa de trabalho pormenorizado sobre o seguimento dos objetivos dos sistemas de educação e de formação. Jornal Oficial das Comunidades Europeias, n. 142, jun. 2002.

DECLARAÇÃO de Bolonha. Declaração conjunta dos ministros da Educação Europeus. 1999. Disponível em:

<http://www.ond.vlaanderen.be/hogeronderwijs/bologna/links/language/1999_Bologna _Declaration_Portuguese.pdf>. Acesso em: 5 jul. 2013.

DELORS, J. (Coord.). Educação, um tesouro a descobrir: relatório para a UNESCO da Comissão Internacional sobre Educação para o século XXI. Porto: ASA, 1996.

EUROPEAN UNION. A european strategy for smart, sutentainabel and Inclusive Growth. Bruxelas: Comissão Europeia, 2010.

FALEIROS, V. P. Estratégias em serviço social. São Paulo: Cortez, 1997. 
FERREIRA, J. B. Bolonha: reconfiguração do ensino superior e desafios curriculares? In: PACHECO, J. A. et al. (Org.). Globalização e (des)igualdades: desafios contemporâneos. Porto: Porto Ed., 2007. pp. 73-82.

FONSECA, H. M. A. C.; BAGO, J.; SANTOS, L. Elderly, education, intergerational relationships and social development. In: CONFERENCE OF ELOA, 2011, Minho. Actas... Minho: Universidade do Minho, 2011. p. 99-109.

GONÇALVES, T. et al. Who are they? making non-traditional students visible. In: POSITIONING and conceptualizing adult education and learning within local development. Istanbul: Bogaziçi University Press, 2011. p. 271-280.

MARQUES, E.; MOURO, H. Portugal. In: CAMPANINI, A.; FROST, E. (Ed.). European social work, commonalities and differences. Roma: Caracci, 2004. p. 182-188.

MARTINS, A. Génese, emergência e institucionalização do serviço social português. Lisboa: Fundação Calouste Gulbenkian, 1999.

. Investigação em serviço social em Portugal contemporâneo: paradoxos e desafios. Revista Locus SOCI@L, Lisboa, n. 1, p. 32-47, 2008.

Serviço social e investigação. In: NEGREIROS, M. et al. Serviço social profissão e identidade: que trajectória? Lisboa: Veras, 1999. p. 45-63.

MARTINS, A; TOMÈ M. R. Estado actual da formação em serviço social em Portugal: problemas e desafios à organização profissional. Disponível em: <www.cpihts.com>. Acesso em: 5 mar. 2008.

MOURO, H.; SIMÕES, D. Cem anos do serviço social. Coimbra: Quarteto, 2001.

PAYNE, M. Continuing and lifelong education for social work, in campus social, Revista Lusófona de Ciências Sociais, Lisboa, n. 2, p. 51-60, 2005.

PLANO TECNOLÓGICO. Plano tecnológico 2020: uma estratégia de crescimento com base no conhecimento, tecnologia e inovação. 2005. Disponível em:

<http://www. planotecnologico.pt/InnerPage.aspx?idCat=34\&idMasterCat=30\&idLang=1 \&site=planotecnologico $>$. Acesso em: 5 mar. 2012.

PORTUGAL. Decreto-Lei no 64/2006a. Regulamenta o acesso aos maiores de 23 anos ao Ensino Superior em Portugal. Diário da República, n. 57, mar. 2006. Disponível em: <http://www.dges.mctes.pt/NR/rdonlyres/946C6824-37AB-476B-A0D4688792D6836F/487/1DL64_06RegulamentaoAcessoaoEnsinoSuperiorparaMaio.pdf>. Acesso em: 5 jul. 2013.

Decreto-Lei no 74/2006b. Regime jurídico dos graus e diplomas do Ensino Superior em Portugal. Diário da República, n. 60, mar. 2006. Disponível em: <http://alfa.fct.mctes.pt/apoios/bolsas/DL_74_2006.pdf>. Acesso em: 5 jul. 2013. 
. Lei no 49 de 30 de agosto de 2005. Segunda alteração à Lei de Bases do Sistema Educativo e primeira alteração à Lei de Bases do Financiamento do Ensino Superior. Diário da República, Lisboa, n. 166, 30 ago. 2005. Disponível em: <http://www.dges.mctes.pt/NR/rdonlyres/40A12447-6D29-49BD-B6B4E32CBC29A04C/1128/L492006.pdf>. Acesso em: 5 jul. 2013.

Recomendação do Parlamento Europeu e do Conselho de 18 de dezembro de 2006c . Sobre as competências essenciais para a aprendizagem ao longo da vida. Jornal Oficial da União Europeia, n. 394, 30 dez. 2006.

SEN, A. Desenvolvimento como liberdade. São Paulo: Companhia das Letras, 2000.

Recebido em: 10/02/2013

Aprovado em: 21/06/2013 